\title{
COVID-19 SOB DOMÍNIO PÚBLICO argumentos de usuários numa rede social
}

COVID-19 UNDER PUBLIC DOMAIN

user's arguments on a social network

Leconte de Lisle Coelho Junior

(iD) http://orcid.org/oooo-0oo2-9451-3303

Uninassau/Campina Grande, Doutor em Psicologia

Stephanny Silva Ferreira

(iD) http://orcid.org/oooo-ooo2-8445-8435

Uninassau/Campina Grande, estudante de Psicologia

Taíse Januário de Oliveira

(iD) http://orcid.org/oooo-0oo1-7073-2539

Uninassau/Campina Grande, estudante de Psicologia

\section{RESUMO}

A pandemia da Covid-19 assola as sociedades de forma indiscriminada, atingindo pessoas de todas as classes sociais e faixas etárias. É um fenômeno de natureza biopsicossocial, e que atinge a saúde física e mental. Esta pesquisa teve como objetivo estudar o discurso relacionado à pandemia na instância do debate público. Uma pesquisa documental foi realizada, com o uso de material de domínio público proveniente de uma rede social, tendo-se como suporte o olhar da psicologia social da saúde. As coletas de dados se deram entre os meses de janeiro e julho do corrente ano, tendo se concentrado nas páginas de dois jornais de grande expressão nacional. Foram coligidas 8.351 respostas, que, após análise textual pelo programa Iramuteq, resultaram em cinco classes: vírus; Deus; Bolsonaro; isolamento; e saúde. Dado relevante, entre outros, é que, quanto mais o tempo passou desde o início do ano, mais as postagens ficaram politizadas.

Palavras-chave: Covid-19; Psicologia Social da Saúde; Iramuteq.

\section{ABSTRACT}

The Covid-19 pandemic has been wiping out the society indiscriminately, affecting people of all social classes and age groups. It is a biopsychosocial phenomenon that affects physical and mental health. This research aimed to study the pandemic-related discourse in the public debate. In order to achieve this goal, a documentary research was carried out through the use 
of public domain material on a social network and it was supported by the perspective of social psychology of health. The data collection took place between the months of January and July of this year and it concentrated on the pages of two newspapers of great national importance. It was collected 8351 answers that, after a textual analysis by the Iramuteq program, resulted in five classes: viruses; God; Bolsonaro; isolation; and health. A relevant fact is that the more time has passed since the beginning of the year the more the posts became politicized.

Keywords: Covid-19; Social Psychology of Health; Iramuteq.

\section{INTRODUÇÃO}

Os primeiros casos detectados do novo coronavírus foram registrados na província de Wuhan, na China. A doença possui uma ampla taxa de contágio, e se propagou rapidamente em mais de 25 países (wu et al., 2020). Resumindo-se de modo simplório, a Covid-19 é considerada uma doença aguda que pode ter seu quadro revertido, com uma taxa inicial de mortalidade baixa (2\%). No entanto, apresenta um risco maior para a população com alguma outra patologia orgânica preexistente. Além disso, a faixa etária parece ser um ponto fulcral no que diz respeito à capacidade de maior ou menor resistência do organismo humano à doença (HUANG et al., 2020).

Os coronavírus (CoVs) consistem em um grupo de vírus pertencente à família Coronaviridae; são vírus que podem vir a ser causadores e/ou complicadores de doenças hepáticas, entéricas, respiratórias e neurológicas com níveis de gravidade variáveis (woo et al., 2009). A diversidade desse grupo de vírus está relacionada tanto com as altas taxas de mutação durante a replicação do seu genoma como também com a incidência nas recombinações homólogas no genoma e com o tamanho desse genoma em comparação a outros vírus de RNA (DUFFY; SHACKELTON; HOLMES, 2008; LAI, 1992).

Segundo pesquisadores na área de infectologia, o principal meio de transmissão do Sars-CoV-2 são as secreções respiratórias e outros diversos fluidos corporais, provenientes de pessoas infectadas, bem como o contato direto com objetos e superfícies contaminadas (YANG; WANG, 2020). No cenário atual, ainda não existem fármacos ou vacinas específicas para o tratamento ou 
prevenção da Covid-19. Desse modo, a comunidade científica se vê inserida em um cenário totalmente atípico e desafiador. Há a presença de lacunas no que se refere ao entendimento dos mecanismos da patologia e falhas relacionadas ao diagnóstico, tentativas de tratamento e meios de prevenção (sANTOs; LIMA et al., 2020; SANTOS; NUNEs et al., 2020).

A pandemia tem permitido vastas reflexões sobre questões que passavam despercebidas no cotidiano da maioria da população mundial. O surto virótico sem tratamento específico, sem vacinas e sem proteção adequada deixou as pessoas em situação de vulnerabilidade, exposição e risco. Conforme Pinho (2020), tal contexto fez com que os diversos governos e os cidadãos pensassem sobre os padrões de saúde adotados tanto pelos Estados como por cada pessoa, sobre o direito básico à saúde e a garantia de acesso aos meios de distribuição dos recursos, sobre a atuação e as posturas dos governantes, nos níveis municipal, estadual, federal e mundial, acerca da proteção de seus compatriotas.

Domingues e colaboradores (2020) ressaltam, atualmente, a existência de uma ampla discussão na sociedade acerca dos impactos econômicos gerados pelas medidas de isolamento e sobre virem sendo estas implementadas de forma muito intensa ou errônea. A sociedade, e aqui se dá ênfase ao Brasil, parece ter dificuldade de avaliar os possíveis benefícios que as estratégias de isolamento físico trazem quando se fala em termos de fatalidade, como complicações de saúde, óbitos, infecções e problemas econômicos. No que tange à salvaguarda econômica, a preservação da vida é, de forma redundante, vital, pois está ligada ao cuidado com a força do trabalho ou mão de obra e com o consumo de bens e serviços.

$\mathrm{O}$ achatamento da curva de contaminação é medida fundamental para se evitar o colapso dos sistemas de saúde, não apenas no Brasil, mas em todos os países (BARRETo et al., 2020; coDEço et al., 2020). Por outro lado, a taxa de isolamento social tem sido distinta entre os diferentes estados e municípios brasileiros (sCHUCHMANN et al., 2020). Após algumas semanas de isolamento, o que nem sempre teve uma boa adesão em alguns lugares, principalmente em cidades pequenas, onde a vida parece seguir normalmente, observou-se a presença de uma queda no distanciamento, mesmo ainda numa fase ascendente da curva de contaminação. Essa queda da taxa de isolamento pode estar ligada a dificuldades de percepção do benefício proporcionado pelo distanciamento (DOMINGUES, 2020). 


\section{PSICOLOGIA SOCIAL DA SAÚDE}

A psicologia social da saúde revela a importância do modelo biopsicossocial, que não está restrito ao reconhecimento do papel ativo individual no processo de resposta (positiva ou negativa) à doença, mas evidencia uma visão integrada da mesma (LIMA; BERNARDES; MARQUES, 2010). Essa abordagem enfatiza toda a subjetividade do sujeito, levando em consideração todos os aspectos e fatores que envolvem, direta e indiretamente, o ser. A psicologia social da saúde, que tem como base intervenções coletivas, se apresenta como grande aliada das populações carentes, pois consegue construir formas variadas de intervenções para o campo da saúde fora do tradicional modelo biomédico (AGUIAR; RONZANI, 2007).

Ainda seguindo essa linha de pensamento, a psicologia social da saúde representa um crescimento da visão individual da saúde/doença para uma compreensão mais social e menos médica, o que a aproxima de abordagens como a psicologia comunitária (LIMA; BERNARDES; MARQUES, 2010).

No Brasil, Spink (2013) consolidou tal concepção quando identificou que as temáticas relacionadas à saúde somente se encaixam na realidade nacional quando as pessoas, isto é, os usuários, conseguem dar sentido aos processos de prevenção e promoção da saúde, seja física, seja mental. E isso significa se aproximar constantemente da população mais vulnerável. Nesse sentido, os psicólogos podem mediar as relações entre as pessoas e o conhecimento técnico-científico, a fim de que elas possam usufruir do seu direito ao Sistema Único de Saúde (sus) (SPINK, 2010).

Desse modo, a consequência direta de tal contexto é a presença marcante desse profissional dentro das equipes interdisciplinares e dentro das instituições de saúde (AGUIAR; RONZANI, 2007).

Levando em consideração que a discussão sobre a saúde no Brasil transcende os limites impostos a este texto, é necessário expressar que esta pesquisa teve como objetivo estudar os discursos relacionados à pandemia da Covid-19 por leitores de dois jornais muito expressivos para a mídia deste país, em uma rede social.

\section{MÉTODO}

Embora a disseminação internacional da Covid-19 tenha chamado mais atenção em janeiro, o primeiro caso no Brasil foi reportado no mês de fevereiro (DONG; HU; GAO, 2O2O; HUANG et al., 2020; MACEDO; ORNELLAS; BONFIM, 2020; wU et al., 2020). Tendo em vista o número crescente de vitimados pela pandemia, resolveu-se mapear os discursos vinculados a ela por usuários de uma 
rede social. Sendo assim, decidimos realizar uma pesquisa documental no âmbito do domínio público.

A internet é um local onde facilmente se pode conseguir acesso a uma grande quantidade de pessoas em pouco tempo (FRAGOso; RECUERO; AMARAL, 2011); por isso, foi escolhida uma rede social de largo uso para coletar dados dos discursos de leitores de dois jornais de grande expressão nacional (O Estado de S. Paulo e Folha de S. Paulo), sediados na cidade de São Paulo, no período de janeiro a julho de 2020.

Foi realizada, em seguida, a análise textual dos argumentos escritos $(N=8.351)$ nas páginas on-line daqueles jornais. Uma mesma pessoa pode ter tido seus argumentos escritos capturados, através do print para a realização da pesquisa, mais de uma vez. Como critério de inclusão, foram selecionados os comentários de resposta à publicação. Já como critério de exclusão, utilizou-se a eliminação de respostas a comentários, e também a eliminação de comentários que tinham apenas símbolos ou menos de três palavras. A Classificação Hierárquica Descendente (CHD) destaca os elementos presentes nas respostas dos participantes. Seu principal objetivo consiste em gerar classes de palavras, geralmente separadas por cor, que são semelhantes entre si, diferentes de outras classes, e que aparecem com maior frequência (sousA; GONDIM; CARIAS; BATISTA; MACHADO, 2020).

O programa Iramuteq foi utilizado para a análise textual, levando em conta que os assuntos, uma vez capturados, eram digitados em Word para posterior exame em conformidade com o exposto por Camargo e Justo (2013). O Iramuteq é um software gratuito desenvolvido por Pierre Ratinaud, docente da Université de Toulouse (França), que possibilita análises estatísticas sobre corpora textuais e sobre tabelas indivíduos/palavras (sousA et al., 2020).

\section{RESULTADOS}

O corpus textual analisado na pesquisa foi composto por 8.351 textos (8.351 respostas), que o programa repartiu em 9.103 segmentos de textos (sTs), que continham, por sua vez, 12.316 palavras ou formas distintas, ocorridas estas, por fim, 143.862 vezes. Para a análise que se seguiu, foram consideradas as palavras com frequência igual ou superior a 3 e com $\chi^{2}>=3,477$. A cHD reteve 79,09 \% do total de sTs, gerando cinco classes. Após a redução dos vocábulos às suas raízes, obtiveram-se 23.547 lematizações, que resultaram em 17.724 palavras ou formas ativas analisáveis. Na Figura 1, que 
se segue abaixo, apresentamos as classes nas quais os discursos ficaram divididos a partir do uso do Iramuteq.

\section{Figura 1. As cinco classes da análise textual}

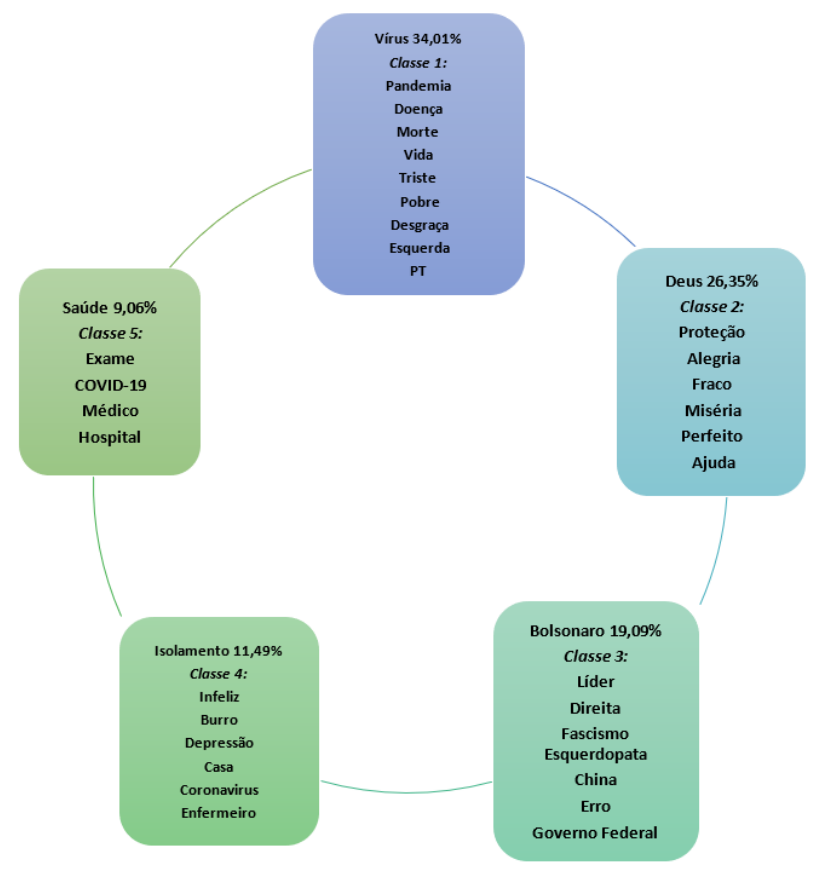

Fonte: Os autores

A primeira classe foi designada de "vírus" e obteve 34,01\% do total de argumentações, expostas nos prints das matérias relacionadas à Covid-19, entre janeiro e julho de 2020. Fazem parte dessa classe palavras como: pandemia, doença, morte, vida, triste, pobre, desgraça, esquerda e PT. Já a segunda classe ("Deus") arrematou $26,35 \%$ das argumentações exibidas, sendo as palavras mais relevantes: proteção, alegria, fraco, miséria, perfeito, ajuda. A terceira classe, definida como "Bolsonaro" (19,09\%), possui como palavras principais: líder, direita, fascismo, esquerdopata, China, erro, Governo Federal. A quarta classe, "Isolamento" (11,49\%), é constituída por: infeliz, burro, depressão, casa, coronavírus e enfermeiro. E, por fim, a quinta e última classe, "Saúde", com 9,06\%, contendo: exame, Covid-19, médico e hospital.

Como complemento da interpretação dos dados, a Figura 2, gerada pelo Iramuteq, acima, apresenta a análise de similitude, que é, conforme Camargo e Justo (2013), uma maneira de perceber a interligação das palavras evocadas pelos leitores. Nesse caso, pelos leitores de O Estado de S. Paulo e da Folha de S. Paulo. 


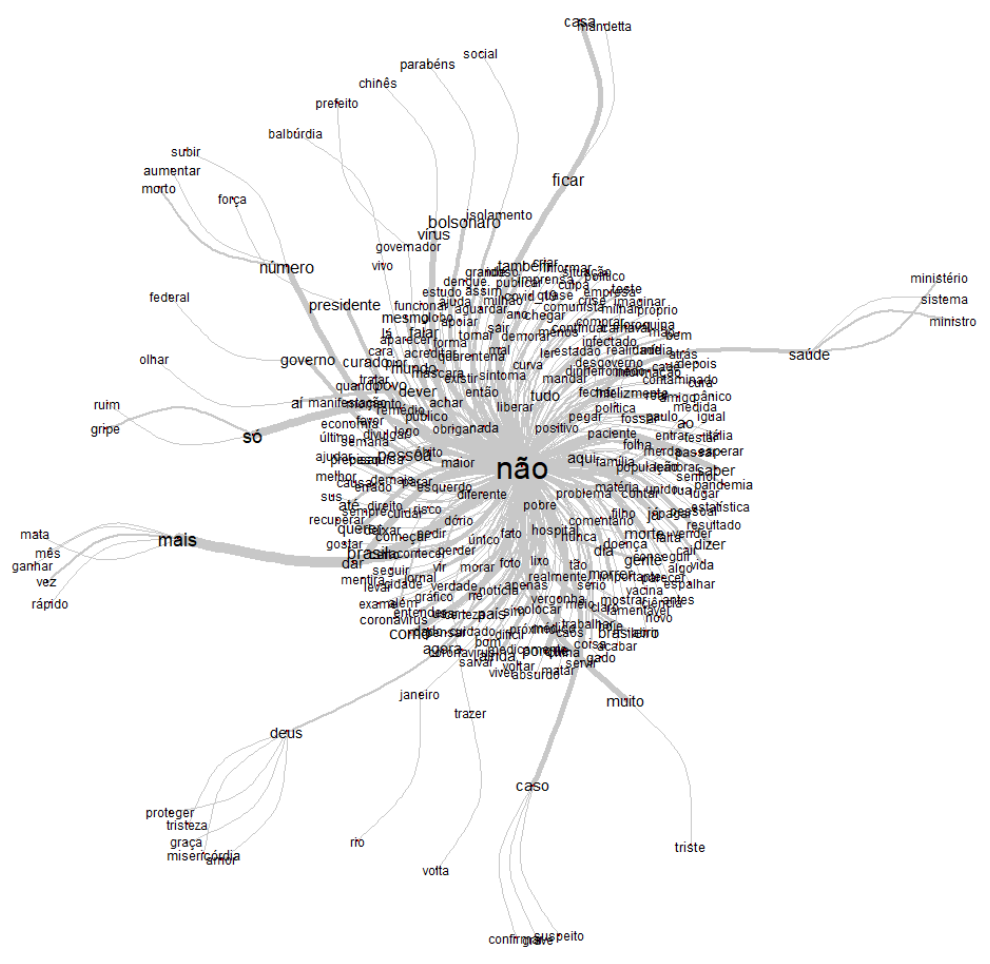

Fonte: Os autores

A palavra "não" aparece em notoriedade na análise de similitude da Figura 2. Pode-se afirmar que essa palavra se apresenta em forma central por dois motivos: primeiro, como uma negação diante do novo coronavírus nos primeiros meses do ano, pois se duvidava da possibilidade de eclosão de casos no país e da probabilidade da instalação da pandemia. Em segundo plano, o "não" pode espelhar a falta de credibilidade quanto à divulgação dos números de casos confirmados no país, visto que muitos dos seguidores desses dois jornais acreditam, segundo os comentários, na ocultação dos números reais ou mesmo na modificação de forma exacerbada destes para criar situações de pânico.

Expressamente, essa última condição é muito perceptível nos comentários ao longo do primeiro semestre do ano de 2020. No entanto, a palavra "não" não se consolida a tal ponto de ser uma evocação por si só fundamental que possa ser definida como uma classe. Ao contrário, ela perpassa todas as classes formadas. 


\title{
DISCUSSÃO
}

A classe 1, nomeada "Vírus", com 34,01\%, tem as seguintes palavras em evidência: pandemia, doença, morte, vida, triste, pobre, desgra$c ̧ a$, esquerda, $P T$. Essa classe abarca os comentários com conteúdos que se referem a estratos sociais mais vulneráveis economicamente, explanando que são as pessoas que mais sofrem com as doenças, habitando os lugares onde ocorrem mais óbitos, devido às precárias condições de acesso a recursos essenciais para tratar a doença (LEMOS; ALMEIDA-FILHO; FIRMO, 202O; MACEDO, ORNELLAS; BONFIM, 2020).

As palavras pandemia, morte, pobre, desgraça e triste relacionam-se de forma intrínseca, pois a doença caracteriza uma ruptura com a rotina, tornando mais veemente a sua realidade repleta de necessidades, causando o vazio existencial derivado da falta de insumos que protejam as pessoas de forma geral e, em específico, as mais pobres. É como se o vírus personificasse a morte.

Codeço (2020) expressa que a dispersão do vírus se dá de maneira extremamente rápida em locais com alta densidade demográfica e com grandes níveis de desigualdade social. Além disso, quanto mais pessoas comprimidas num espaço onde não se tem controle da higiene, mais difícil é assegurar que o vírus não se espalhará.

Isso porque, para esse grupo de pessoas, refletem-se as privações sofridas por eles de um dos princípios básicos da vida, que é o acesso à saúde (SPINK, 2013). O seguinte comentário feito pelo usuário n 1.309 evidencia essa classe: "Testes para toda a população! Cadê os testes para a população? Tão pensando que aqui

\author{
f6 \\ A palavra 'não' aparece em \\ notoriedade na análise de \\ similitude [...], como uma negação \\ diante do novo coronavírus \\ nos primeiros meses do ano
}


é a china. Vai morrer todo mundo na rua. Para sair um hospital aqui são 5 anos no mínimo. Tinha nem que deixar quem foi para a china vir para cá até a parada ser controlada”. Esse comentário revela uma falta que é setorializada, pois, embora não haja testes para detecção da Covid-19 em abundância, eles estão à disposição dos mais abastados da população. Essa percepção é bem realçada quando se compreende a questão racial respaldando a desigualdade social na área de saúde (BARRETO et al., 2020; GOES, RAMOs; FERREIRA, 2O2O; MACEDO, ORNELLAS; BONFIM, 202O). Por seu turno, a fala do usuário no 232 exprime a revolta: "Só serve pra mostrar o quanto nos falta em gestão de saúde, seja pro covid ou pra qualquer outra enfermidade".

Ainda na mesma classe, é possível identificar comentários que remetem a partidos políticos, como o Partido dos Trabalhadores $(\mathrm{PT})^{1}$, que é considerado um partido de esquerda. Quando aparece em uma classe que discorre acerca do vírus, é em sentido de comparação e críticas, devido ao tempo que esse partido permaneceu no governo. Isso fica evidente na fala do usuário $n^{\circ} 1$, quando diz: "Pior Vírus que já se teve notícia, se chama pt, se instalou por 16 anos no brasil, liquidando com as riquezas do povo e estatais. Ainda bem que fomos vacinados".

De fato, conforme Höfling (2001), a viabilização do acesso das populações mais vulneráveis ao direito às políticas públicas é encabeçada pelo Estado. Quando essa estratégia não surte efeito, em geral, a população se sente lesada e enganada. E foi por isso que surgiu o sus, para gerar este amparo social em termos de saúde, visto que os mais vulneráveis precisavam do acesso à saúde (PAIM, 2009, 2018).

Embora exista o sus, ele aparentemente não possui visibilidade para muitos sujeitos desta pesquisa, podendo ser essa uma condição provocada por direcionamentos ideológicos. Apesar de todo o trabalho desenvolvido por esse sistema e do investimento que há na área, uma parte da população ainda tem acesso ao serviço de forma precária ou não consegue usufruir do mesmo (MOIMAZ, 2010; SPINK, 2010).

Na segunda classe, denominada "Deus", com 26,35\%, as palavras com maior frequência são: proteção, alegria, fraco, miséria,

1 O período de governo considerado de esquerda ganhou espaço e credibilidade para parte dos brasileiros ao mostrar que seu método se pautava na construção de uma política anti-imperialista, exercendo-se a gestão com mais solidariedade em relação à população, principalmente a mais vulnerável, investindo-se na defesa da autodeterminação nacional e interagindo-se com diversos movimentos sociais existentes, em favor dos direitos dos trabalhadores, pela democracia, pelo progresso social e pelo socialismo (ALMEIDA, 2003). 


\section{Devido à situação econômica no país, [...] a medida indicada de manter-se em quarentena gerou controvérsias}

perfeito, ajuda. Essa classe remete à proteção e força que as pessoas buscam em suas crenças religiosas, a fim de encontrar conforto e segurança para enfrentar a situação problemática do cenário atual.

Tais crenças se confirmam nos seguintes comentários, feitos pelo usuário $\mathrm{n}^{\circ}$ 324: "Tanto coisa ruim nesse País e aparece mais essa, só Deus para nos fortalecer e livrar mesmo"; e pelo usuário $\mathrm{n}^{\circ}$ 257: "Deus tem misericórdia, só ele que pode acabar com o terror”. Pietrukowicz (2001) afirma que pela fé, por meio da religião, é que as pessoas buscam o combustível que traz à vida esperanças de dias melhores e que contribui psicologicamente para o enfrentamento de experiências mais dramáticas vivenciadas. É possível dizer que é nessa fé religiosa que muitas pessoas costumam buscar vigor para enfrentar as angústias e não deixar apagar a coragem e a empatia que as tornam capazes de enfrentar experiências negativas como uma coletividade razoavelmente coesa.

A terceira classe tem com maior frequência as palavras líder, direita, fascismo, esquerdopata, China, erro, Governo Federal, e compõe a classe denominada "Bolsonaro", com 19,09\%. Nessa classe, é possível encontrar comentários como "Atitude de um governo não profissional que age como uma avestruz. Infelizmente, precisa passar por isso para o povo aprender", do usuário $\mathrm{n}^{\circ} 1.365$, que traz à tona a polarização ideológica e política que se firmou no país nos últimos anos. De fato, nas postagens, percebemos que, a cada mês que se passava, as pessoas cada vez mais asseguravam tal situação de choque ideológico, uns contrários e outros favoráveis ao presidente.

Conforme Aguiar e Ronzani (2007), as ideologias atravessam não somente as políticas públicas, mas também as práticas no seio 
da psicologia social da saúde, sendo, portanto, necessária, aos profissionais que seguem esta teoria, a compreensão de que eles devem descortinar os obstáculos para se chegar aos direitos sociais e ao sentido de cidadania. Por isso, encarar as evocações China, esquerdopata, fascismo etc., de forma despreparada, pode levar as pessoas a enviesar os debates sobre uma real solução dos problemas decorrentes da pandemia.

Essa disputa ideológica, entre os apoiadores e os que se opõem, acaba por colocar as medidas tomadas pelo Governo Federal para o combate ao novo coronavírus no país em permanente escrutínio (MACEDO; ORNELLAS; BONFIM, 2020), por meio do qual as pessoas indicam constantemente os "erros” do grupo adversário.

Uma das consequências advindas da pandemia é a crise econômica que emerge em meio a este cenário. Para Lemos, AlmeidaFilho e Firmo (2020), não há espaço para questionamentos sobre a dicotomia entre salvar vidas ou salvar a economia, discurso elaborado pelo presidente da república em sua gestão da pandemia no país. Para os autores supracitados, salvar vidas agora significa salvar a economia mais tarde.

Ainda na mesma classe, os discursos que parecem buscar justificar o aparecimento do vírus em função dos interesses políticos são contundentes. Uma tal afirmação é evidenciada em comentários como: "Sinceramente, eu não tenho muita simpatia pelo presidente, agora tudo que acontece dentro do país culpam o Bolsonaro. Eta povinho idiota. Se acham melhores e são na verdade piores ou iguais aquilo que julga", do usuário no 2.743. O usuário n³.622, por sua vez, diz: “Governo federal é uma piada”. E o usuário no 2.756 afirma que: "O sucesso do combate ao corona aqui no brasil se deve aos governadores ignorando o presidente”. Estes comentários expressam a visão dos seguidores com respeito às medidas que sugerem ou foram tomadas pelos agentes da União.

As palavras infeliz, burro, depressão, casa, coronavirus e enfermeiro estão inseridas na classe denominada "Isolamento", que é a quarta, com $11,49 \%$. Esse conjunto de palavras traz à tona comentários relacionados a uma das medidas preventivas mais eficazes de acordo com a oms, o isolamento social, a fim de controlar o avanço do número de contaminados pelo novo coronavírus no país (sCHUCHMANN et al., 2020). Devido à situação econômica no país, onde há milhares de desempregados, a medida indicada de manter-se em quarentena gerou controvérsias, pois, enquanto há quem defenda e decida cumprir a indicação, há também 
seguidores dos jornais que são contra, alegando ser o trabalho um meio imprescindível de suprir necessidades básicas suas, como a alimentação.

O usuário ${ }^{\circ} 3.649$ confirma essa ideia através de seu comentário, escrevendo: "Eu tenho uma amiga que trabalha em uma empresa de marmitas. E não parou e nem vai parar". Por sua vez, o usuário n 3.577 afirmou que: "147 bilhões para que se ninguém pode sair de casa". O usuário $\mathrm{n}^{\circ} 3.508$ avalia: "O revoltante é ver esse povo nos restaurantes e bares como se nada estivesse acontecendo. Vejo isso da minha janela". Já o usuário no 3.388 diz: "Não precisa parar, mas algumas medidas para conter a propagação são necessárias para conter o avanço. E por pouco tempo se formos espertos". Esta classe indica uma certa desmotivação relacionada ao estado depressivo e de infelicidade geral que atingiu a nação. O humor nacional, outrora tão festejado, alcançou aparentemente um ponto baixo (LIMA, 2020).

A palavra enfermeiro designa um dos principais personagens da pandemia. Os enfermeiros são os profissionais que estão na linha de frente no combate à Covid-19. Esses trabalhadores receberam um impacto psicológico muito forte pelo fato de a doença ter se alastrado em todo mundo rapidamente e de os sistemas de saúde não estarem preparados (BARBOSA; GOMEs; SOUZA; GOMES, 2020). 
Por fim, com 9,06\%, a quinta classe, "Saúde", traz as seguintes palavras: exame, Covid-19, médico e hospital. Essas palavras remetem ao bem-estar no que diz respeito à pandemia. Essa é a menor classe deste estudo. Vejamos alguns comentários: “Todo cuidado é pouco. Não podemos construir hospital em dez anos, nem atender em meses ou anos, ou será com certeza uma pandemia. Sorte que temos a Amazônia como laboratório", do usuário $\mathrm{n}^{\circ}$ 110. O usuário nº 3.391 escreveu que: "sus faz tempos que não oferece nem uma consulta, imagina nessa atual situação. A diferença vai estar entre morrer nos corredores ou não conseguir sequer entrar no PA". E o usuário n 3.458: "Isso porque eles só estão fazendo testes para confirmar em quem apresenta sintomas graves. Na prática com certeza já são muitos mais infectados”. Mais uma vez, percebe-se a desvalorização em relação ao sus. Isso, por sua vez, engloba os serviços médicos e o local onde, em geral, eles são realizados: o hospital.

Considerando-se que o sus é a estrutura estatal que, no campo da saúde, protege, cuida, acolhe, previne e promove ações de saúde (PAIM, 2009), estas pessoas parecem ter um olhar invertido sobre o sistema. É como se o sus não tivesse condições prévias de lidar com a Covid-19, e apenas gerasse custos aos cidadãos. A própria evocação da doença já também é um indicativo do impacto psicológico que a enfermidade causa nas pessoas, gerando desgaste emocional e descrença nos profissionais e em suas técnicas e exames.

Mediante a gravidade e as incertezas apresentadas pelo cenário pandêmico atual, constata-se o detrimento psicológico da população de forma geral, que faz surgir sentimentos como medo, pânico e agressividade (DUAN; ZHU, 2020). Talvez o impacto psicológico mais negativo seja a perda da empatia, sendo esta substituída por "lutas digitais" de cunho ideológico e por aglomerações propositais. Conforme Sen (2010), essa situação impede que as pessoas cresçam espiritualmente e ascendam empaticamente, impedindo o estabelecimento do bem-estar psíquico suficiente para que elas se sintam em harmonia consigo e com seus pares sociais.

\section{CONSIDERAÇÕES FINAIS}

A pandemia do novo coronavírus se alastra pelo mundo, impulsionando as comunidades científicas de diversos países a trabalharem de forma acelerada e, muitas vezes, no formato de convênio, isto é, unidas em prol de um objetivo em comum: a promoção à saúde da humanidade contra esse microrganismo que a surpreendeu. 
Esta pesquisa teve como objetivo explorar o discurso de usuários de uma rede social sobre a pandemia, registrado nas páginas de dois jornais importantes no país. Percebeu-se, com a análise textual desenvolvida a partir do programa Iramuteq, que, parcialmente, os discursos dos usuários expressam críticas ao sistema de saúde brasileiro. Todavia, é necessário pontuar que o Brasil possui um dos maiores e mais consistentes sistemas nacionais de saúde pública.

Uma limitação desta pesquisa foi a impossibilidade de identificar as classes sociais dos usuários da rede social de onde proveio o corpus do estudo. É necessário destacar que, atualmente, o acesso à internet e a redes sociais é muito amplo, atravessando os limites entre as classes sociais. Assim, as críticas direcionadas ao sus podem vir tanto de seus usuários quanto daqueles que não buscam seus préstimos, ou daqueles que o desprezam por pensarem ser uma criação da "esquerda" e que, portanto, deve ser aniquilado.

Isso pode ser explicado porque, na medida em que o tempo foi passando, as argumentações das pessoas foram ficando cada vez mais divididas em uma polarização ideológica contundente entre os que apoiavam o Governo Federal e os que contra ele ficaram. Essa disputa vazia e sem objetivo prático se ampliou pelos discursos nos comentários e, por isso, se encontra em maior ou menor grau em todas as classes concebidas pelo Iramuteq.

Todos os esforços são necessários para se entender não somente a história natural do vírus, mas, também, o efeito que ele obteve sobre as pessoas, incluindo os aspectos psicológicos que podem ser devastadores. E talvez a perspectiva de alguns grupos sociais e militantes seja utilizar essas retóricas a fim de desviar propositalmente a atenção do problema real que é a pandemia, e, assim, manter um equilíbrio emocional baseado na raiva e na antipatia, o que notadamente não é a melhor resposta para uma situação que flagela milhões de pessoas.

Portanto, é necessário direcionar o foco para a psicologia social da saúde como uma proposta que possa efetivamente ajudar as pessoas numa situação tão dura, pela qual todas as sociedades passam. Isso pode, ao menos, ocorrer a partir de processos de conscientização, psicoeducação, presença de psicólogos nas comunidades (principalmente nas mais carentes) realizando o enlace com os seus moradores, criando elos de resistência à doença, e não deixando esmorecer a união entre eles, pois quando a coesão grupal tende a se romper, a resistência contra aquilo que macula o corpo e a psique se esmaece, e a vulnerabilidade social se institui. 


\section{REFERÊNCIAS}

AGUIAR, Silvia Gomes; RONZANI, Telmo Mota. Psicologia social e saúde coletiva: reconstruindo identidades. Psicol. pesq., Juiz de Fora, v. 1, n. 2, p. 11-22, dez. 2007. Disponível em: http://pepsic.bvsalud.org/scielo.php?script=sci_arttext\&pi$\mathrm{d}=$ S1982-12472007000200003\&lng=pt\&n $\mathrm{rm}=$ iso. Acesso em: 22 jul. $202 \mathrm{O}$.

ALMEIDA, Paulo Roberto de. A política internacional do partido dos trabalhadores: da fundação à diplomacia do governo Lula. Rev. Sociol. Polit., Curitiba, n. 20, p. 87102, jun. 2003. Disponível em: http://www. scielo.br/scielo.php?script=sci_arttext\&pi$\mathrm{d}=$ So104-44782003000100008\&lng=en\&nr $\mathrm{m}=$ iso. Acesso em: 20 jul. 2020.

BARBOSA, Diogo Jacinto; GOMES, Már-cia Pereira; SOUZA, Fabiana Barbosa A.; GOMES, Antônio M. T. Fatores de estresse nos profissionais de enfermagem no combate à pandemia da Covid-19. Comunicação em ciências da saúde, Brasília, DF, v. 31, p. 31-47. Sup. 1. Disponível em: http://www. escs.edu.br/revistaccs/index.php/comunicacaoemcienciasdasaude/article/view/651. Acesso em: 20 jul. 2020.

BARRETO, Maurício Lima et al. O que é urgente e necessário para subsidiar as políticas de enfrentamento da pandemia de Covid-19 no Brasil? Rev. bras. epidemiol., Rio de Janeiro, v. 23, 2020. Disponível em: http://www. scielo.br/scielo.php?script=sci_arttext\&pi$\mathrm{d}=\mathrm{S} 1415-790 \mathrm{X} 2020000100101 \& \operatorname{lng}=\mathrm{en} \& \mathrm{nr}$ $\mathrm{m}=$ iso. Acesso em: 02 jul. 2020.

CAMARGO, Brigido Viseu; JUSTO, Ana Maria. IRAMUTEQ: Um software gratuito para análise de dados textuais. Temas psicol., Ribeirão Preto, v. 21, n. 2, p. 513-518, dez. 2013. Disponível em: http://pepsic.bvsalud.org/scielo.php?script=sci_arttext\&pi$\mathrm{d}=\mathrm{S} 1413-389 \mathrm{X} 2013000200016 \& \operatorname{lng}=\mathrm{pt} \& \mathrm{nr}$ $\mathrm{m}=$ iso. Acesso em: 5 fev. 2020.

CODEÇO, Cláudia et al. Estimativa de risco de espalhamento da Covid-19 no Brasil e avaliação da vulnerabilidade socioeconômica nas microrregiões brasileiras. Rio de Janeiro: Fiocruz, 2020.

DOMINGUES, Edgar et al. Cenários de isolamento social da Covid-19 e impactos econômicos em Minas Gerais. Belo Horizonte: Cedeplar, 2020.

DONG, Liying; HU, Shasha; GAO, Jianjun. Discovering drugs to treat coronavirus di- sease 2019 (COVID-19). Drug Discoveries \& Therapeutics, Tokyo, v. 14, n. 1, p. 58-60, 2020. Disponível em: https://pubmed.ncbi.nlm.nih.gov/32147628/. Acesso em: 10 jul. 2020.

DUAN, Li; ZHU, Gang. Psychological interventions for people affected by the COVID-19 epidemic. The Lancet, London, v. 7 , n. 4, p. 300-302, 2020. Disponível em: https://pubmed.ncbi.nlm.nih.gov/32085840/. Acesso em: 10 jul. 2020.

DUFFY, Siobain; SHACKELTON, Laura A.; HOLMES, Edward C. Rates of evolutionary change in viruses: Patterns and determinants. Nat Rev. Genet., London, v. 9, n. 4, p. 267-276, 2008. Disponível em: https://www. nature.com/articles/nrg2323? proof=true\#citeas. Acesso em: 09 jul. 2020.

FRAGOSO, Suely; RECUERO, Raquel; AMARAL, Adriana. Métodos de pesquisa para internet. Porto Alegre: Editora Sulina, 2011.

GOES, Emanuelle Freitas; RAMOS, Dandara de Oliveira; FERREIRA, Andrea Jacqueline Fortes. Desigualdades raciais em saúde e a pandemia da Covid-19. Trab. educ. saúde, Rio de Janeiro, v. 18, n. 3 , 2020. Disponível em: http://www.scielo. br/scielo.php?script=sci_arttext\&pid=S1981 $-77462020000300301 \& \operatorname{lng}=$ en\&nrm=iso. Acesso em: 19 jul. 2020.

HOFLING, Eloisa de Mattos. Estado e políticas (públicas) sociais. Cad. Cedes, Campinas, v. 21, n. 55, p. 30-41, nov. 2001. Disponível em: http://www.scielo.br/scielo. php?script=sci_arttext\&pid=So101-326220 $01000300003 \& \operatorname{lng}=$ en \&nrm=iso. Acesso em: 19 jul. 2020.

HUANG, Chaolin et al. Clinical features of patients infected with 2019 novel coronavirus in Wuhan, China. Lancet, London, v. 395, n. 10223, p. 497-506, 2020. Disponível em: https://www.thelancet.com/journals/ lancet/article/PIISo140-6736(20)30183-5/ fulltext. Acesso em: 20 jul. 2020.

LAI, Michael Ming-Chiao. RNA recombination in animal and plant viruses. $M i$ crobiol. Rev., São Paulo, v. 56, n. 1, p. 6179, 1992. Disponível em: https://pubmed. ncbi.nlm.nih.gov/1579113/.Acesso em: 20 jul. 2020.

LEMOS, Pedro; ALMEIDA-FILHO, Naomar; FIRMO, Josélia. COVID-19, desastre 
do sistema de saúde no presente, tragédia da economia em um futuro bem próximo. BJIHS, Macapá, v. 2, n. 4, p. 39-50, 2020. Disponível em: https://www.researchgate.net/publication/341001384. Acesso em: 20 jul. 2020.

LIMA, Rossano Cabral. O distanciamento e o isolamento sociais pela Covid-19 no Brasil: Impactos na saúde mental. Physis, Rio de Janeiro, v. 30, n. 2, 2020. DOI: doi. org/10.159o/So103-73312020300214.

LIMA, Maria Luisa, BERNARDES, Sonia; MARQUES, Sibila. Psicologia social da saúde: investigação e intervenção em Portugal. Lisboa: Silabo, 2010.

MACEDO, Yuri M.; ORNELLAS, Joaquim L.; BOMFIM, Helder E. Covid-19 no Brasil: O que se espera para população subalternizada? Revista Encantar - Educação, Cultura e Sociedade, Bom Jesus da Lapa, v. 2, p. 1-10, 2020. Disponível em: http:// www.revistas.uneb.br/index.php/encantar/ article/view/8189. Acesso em: 20 jul. 2020.

MOIMAZ, Suzely Adas Saliba et al. Satisfação e percepção do usuário do SUS sobre o serviço público de saúde. Physis, Rio de Janeiro, v. 20, n. 4, p. 1419-1440, dez. 2010. Disponível em: http://www.scielo. br/scielo.php?script=sci_arttext\&pid=So 103-73312010000400019\&lng=pt\&nrm=iso. Acesso em: 19 jul. 2020.

PAIM, Jairnilson Silva. Sistema Único de Saúde (SUS) aos 30 anos. Ciênc. saúde coletiva, Rio de Janeiro, v. 23, n. 6, p. 17231728, jun. 2018. Disponível em: http://www. scielo.br/scielo.php?script=sci_arttext\&pi$\mathrm{d}=\mathrm{S} 1413-81232018000601723 \& \operatorname{lng}=\mathrm{en} \& \mathrm{nr}$ $\mathrm{m}=$ iso. Acesso em: 19 jul. 2020.

PAIM, Jailmilson S. O que é o SUS? Rio de Janeiro: Fiocruz, 2009.

PIETRUKOWICZ, Márcia C. L. Cypriano. Apoio social e religião: uma forma de enfrentamento dos problemas de saúde, 2001. Dissertação (Mestrado em Saúde Pública) - Escola Nacional de Saúde Pública Sergio Arouca - Fiocruz, Rio de Janeiro, 2001.

PINHO, Simone B. A Atenção Primária à Saúde no contexto da Covid-19. HU Revis$t a$, Juiz de Fora, v. 46, p. 1-2, 2020. Disponível em: https://periodicos.uff.br/index. php/hurevista/article/view/30077. Acesso em: 9 jul. 2020.

SANTOS, Felipe R. S.; LIMA, Willian G. et al. Identification of a potential Zika Virus inhibitor targeting $\mathrm{NS}_{5}$ methyltransferase using virtual Screening and molecular dynamics simulations. J. Chem. Inf. Model., Washington, v. 6o, n. 2, p. 562-568, 2020. Disponível em: https://pubs.acs.org/doi/ abs/10.1021/acs.jcim.9boo809. Acesso em: 5 jul. 2020.

SANTOS, Felipe R. S.; NUNES, Damiana, A. F. et al. Identification of Zika Virus NS${ }_{2} \mathrm{~B}-\mathrm{NS} 3$ protease inhibitors by structure-based virtual screening and drug repurposing approaches. J. Chem. Inf. Model., Washington, v. 6o, n. 2, p. 731-737. Disponível em: https://pubs.acs.org/doi/abs/10.1021/acs.jc im.9boo933. Acesso em: 5 jul. 2020.

SCHUCHMANN, Alexandra Z.; SCHNORRENBERGER, Bruna L.; CHIQUETTI, Maria E.; GAIKI, Raiane S.; RAIMANN, Bruno W.; MAEYAMA, Marcos A. Braz. J. Hea. Rev., Curitiba, v. 3, n. 2, p. 3556-3576 mar./abr. 2020. Disponível em: https://www.brazilianjournals.com/ index.php/BJHR/article/view/9128. Acesso em: 3 jul. 2020.

SEN, Amartya. Desenvolvimento como liberdade. São Paulo: Companhia das Letras, 2010.

SOUSA, Yuri S. O., GONDIM, Sonia M. G.: CARIAS, Iago A.; BATISTA, Jonatan S.; MACHADO, Katlyane. C. M. O uso do software Iramuteq na análise de dados de entrevistas. Pesquisas e Práticas Psicossociais, São João del-Rei, v. 15, n. 2, p.1-19., abr./jun. 2020. Disponível em: http://www.seer.ufsj. edu.br/index.php/revista_ppp/article/view/ e3283. Acesso em: 19 jul. 2020.

SPINK, Mary. J. Psicologia social e saúde. Práticas, saberes e sentidos. Petrópolis: Vozes, 2013.

SPINK, Mary. J. Psicologia social e saúde: Trabalhando com a complexidade. Quaderns de psicologia, Barcelona, v. 12, n. 1, p. 42-56, 2010. Disponível em: http://www. quadernspsicologia.cat/article/view/752. Acesso em: 30 mai. 2020.

WOO, Patrick C. Y.et al. Coronavirus diversity, phylogeny and interspecies jumping. Exp. Bio Med, v. 234, n. 10, p.1117-1127, 2009. Disponível em: https://pubmed.ncbi.nlm. nih.gov/19546349/.Acesso em: o1 jul. 2020. WU, Fan et al. A new coronavirus associated with human respiratory disease in China. Nature, London, 579, p. 265-269, 2020. Disponível em: https://www.nature. com/articles/s41586-020-2008-3. Acesso em: 19 jul. 2020. 
YANG, Penghui; WANG, Xiliang. COVID-19: a new challenge for human beings. Cell mol immunol. London, v. 17, n. 5, p. 555-557, 2020. Disponível em: https:// www.nature.com/articles/s41423-020-0407$\mathrm{X}$ \#citeas. Acesso em: 3 jun. 2020.

一椋一

Texto submetido em: 30 jul. 2020. Aprovado em: 2 out. 2020.

COELHO JUNIOR, Leconte de Lisle; FERREIRA, Stephanny Silva; OLIVEIRA, Taíse Januário de. Covid-19 sob domínio público: argumentos de usuários numa rede social. Estudos Universitários: revista de cultura, Recife, v. 37, n. 1/2, p. 137-153, dez. 2020. ISSN Edição Digital: 2675-7354. 